\title{
Prone position surgery for a subcarinal bronchogenic cyst
}

\author{
Toru Nakamura $^{1 *}$ D, Ryo Fujikawa', Yoshiro Otsuki ${ }^{2}$ and Kazuhito Funai ${ }^{3}$
}

\begin{abstract}
Background: Prone position surgery has become widespread for esophageal cancer instead of the traditional lateral decubitus approach. Carbon dioxide insufflation and the gravity effect provide a better operative field without parenchymal retraction. We herein report a case of a subcarinal bronchogenic cyst, which was successfully removed by the prone position surgery.

Case presentation: A 65-year-old man presented with a subcarinal mass and was planned to undergo a surgical resection in the prone position. Although he required bilateral ventilation due to hypoxemia, the excellent operative field was maintained and we completed the thoracoscopic surgery without any additional parenchymal retractions.
\end{abstract}

Conclusions: Thoracoscopic surgery in the prone position is a feasible option for subcarinal tumors with an excellent operative view and would facilitate a solo surgery without the need for a skilled assistant.

Keywords: Prone position, Thoracoscopic surgery, Bronchogenic cyst

\section{Background}

Bronchogenic cysts are rare congenital neoplasms arising from abnormal budding of the bronchial tree and often develop in the mediastinum. Further, video-assisted thoracoscopic surgery (VATS) in the lateral decubitus position has been the standard surgical approach for mediastinal tumors to date [1-3]. In addition, recent reports have suggested the utility of the prone position approach with carbon dioxide $\left(\mathrm{CO}_{2}\right)$ insufflation for esophageal cancer and other mediastinal tumors [4-6]. We herein report a case with a subcarinal bronchogenic cyst that successfully underwent a thoracoscopic resection in the prone position.

\section{Case presentation}

A 65-year-old man presented with a subcarinal mass incidentally found during the preoperative work up for bladder cancer. Magnetic resonance imaging

\footnotetext{
* Correspondence: tonakamu@sis.seirei.or.jp

${ }^{1}$ Department of General Thoracic Surgery, Seirei Hamamatsu General

Hospital, 2-12-12 Sumiyoshi, Hamamatsu, Shizuoka, Japan

Full list of author information is available at the end of the article
}

revealed a circumscribed mass suggesting a bronchogenic cyst (Fig. 1). After completing a trans-urethral resection of bladder cancer, he was referred to our department and planned to undergo a surgical resection of the tumor.

The patient was placed in the prone position and his right arm was raised cranially. Under one-lung ventilation, the initial 5 -mm port was inserted at the fifth intercostal space (ICS) on the right middle axillary line (port 1, Fig. 2). $\mathrm{CO}_{2}$ was insufflated through this port at a pressure of $8 \mathrm{mmHg}$. Under a thoracoscopic view, the second $5-\mathrm{mm}$ port and third $12-\mathrm{mm}$ port were inserted at the ninth ICS on the scapular line (port 2) and seventh ICS on the middle axillary line (port 3), respectively. With the thoracoscope inserted through port 2, the surgeon held a grasper and electrocautery via port 3 and port 1 .

In addition to $\mathrm{CO}_{2}$ insufflation, a gravity effect also facilitated the exposure of the posterior mediastinum and subcarinal mass wide enough without any retraction (Fig. 3a). The mediastinal pleura was incised inferiorly to mobilize the tumor from the pericardium and bronchus (Fig. 3b, c). 


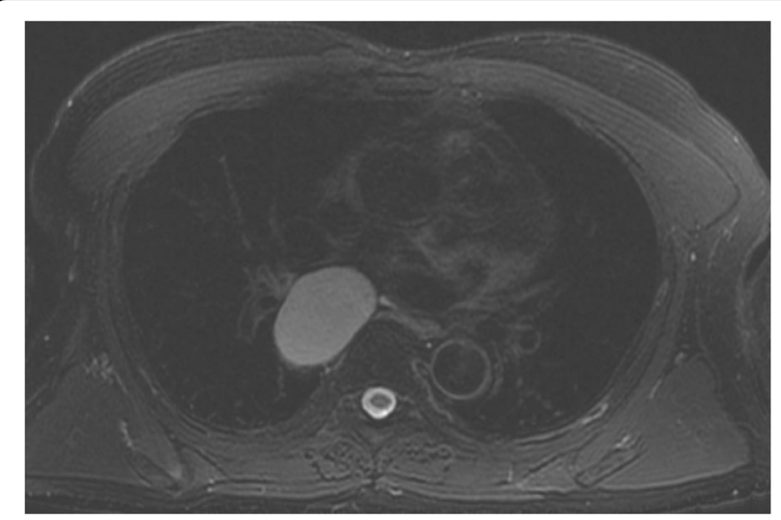

Fig. 1 Axial T2 weighted image showing a cyst in the subcarinal area

However, $10 \mathrm{~min}$ after beginning the surgery, he required bilateral ventilation because of hypoxemia when his $\mathrm{O}_{2}$ saturation dropped to $81 \%$ probably caused by diaphragmatic compression (his body mass index was 25.3). Nevertheless, the operative field was maintained excellently even with bilateral ventilation and we completed the total resection of the tumor successfully (Fig. 3d). The operative time and estimated blood loss were $126 \mathrm{~min}$ and $1 \mathrm{~g}$, respectively. A histological examination revealed that the cyst wall lined by pseudostratified ciliated epithelium contained smooth muscle, consistent with a diagnosis of a bronchogenic cyst. The postoperative course was uneventful, and he was discharged 3 days after surgery.

\section{Conclusions}

Bronchogenic cysts often develop in the mediastinum and require a surgical resection even in asymptomatic patients to prevent complications such as infections, hemorrhage, raptures, and malignant formations [7-10] . Although the lateral decubitus VATS approach has been the standard approach for mediastinal tumors over the decades, we performed the surgery in the prone position in our case. Compared with the traditional lateral decubitus VATS approach, the prone position surgery provides easier access to the posterior mediastinum mainly by the gravity effect. Combined with positive pressure by $\mathrm{CO}_{2}$ insufflation, the lung and heart fall downward and the blood also drips outside the operative field. These factors provided an excellent surgical view without any additional retraction and enabled a solo surgery in our case.

Although the usefulness of a bilateral approach in the decubitus position for subcarinal bronchogenic cysts has been reported, it was deemed to be troublesome because a positioning change of the patient was required during the surgery [11]. Further, the prone position has been reported to facilitate a better lymph node dissection in the subcarinal area than a lateral decubitus position during esophagectomy [12]; however, a unilateral approach in the prone position would be a feasible option for surgery for subcarinal tumors. In addition, the prone position surgery also allowed a left-sided and bilateral approach without any morbidity $[13,14]$. These results suggested that the prone position approach would be more beneficial both for the curability and utility than the lateral decubitus position for the posterior mediastinum surgery. We consider that this surgical approach would be applicable for other types of posterior mediastinal tumors, such as schwannoma located in the superior mediastinum.

Thoracoscopic surgery in the prone position is a feasible option for subcarinal tumors. $\mathrm{CO}_{2}$ insufflation and the gravity effect provide an excellent

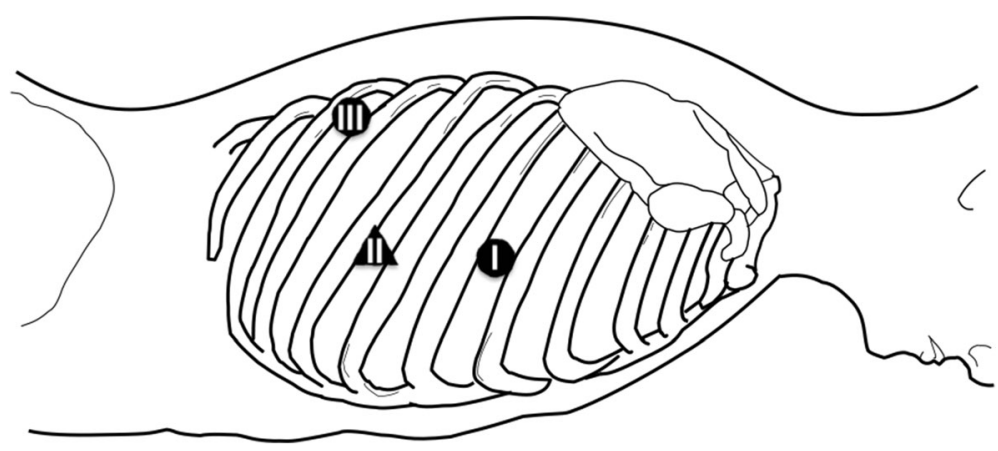

Fig. 2 Patient position and port insertion site 


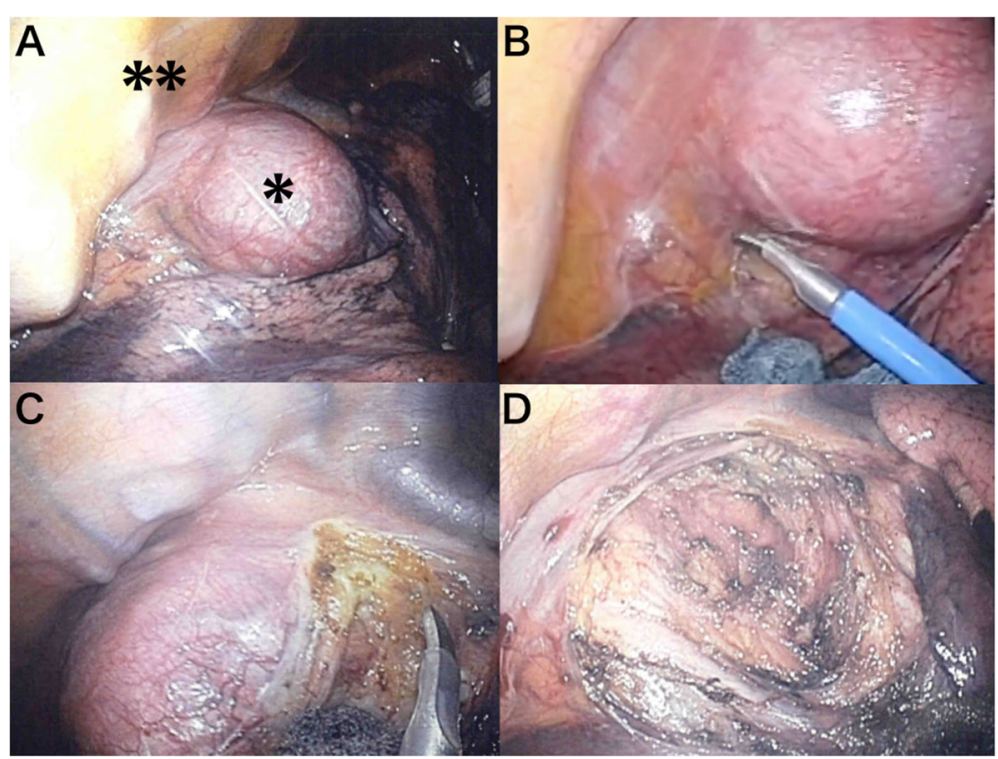

Fig. 3 Operative view in the prone position. a Carbon dioxide insufflation facilitated the exposure of the tumor $\left(^{*}\right)$ anterior to the thoracic vertebra $\left(^{* *}\right)$. b The mediastinal pleura was incised inferiorly to mobilize the tumor from the pericardium. $\mathbf{c}$ By dissecting the pleura toward the cranial direction, the tumor was removed from the bronchus and esophagus. An excellent operative field was maintained even with bilateral ventilation. $\mathbf{d}$ The tumor was completely removed

operative view without any additional parenchymal retraction and might facilitate a solo surgery even with bilateral ventilation.

\section{Abbreviations}

$\mathrm{CO}_{2}$ : Carbon dioxide; ICS: Intercostal space; VATS: Video-assisted thoracoscopic surgery

\section{Acknowledgements}

The authors thank all the people who contributed to this report.

\section{Authors' contributions}

TN performed the operation and wrote this paper. RF and KF helped to draft the manuscript. YO reviewed the pathological finding and revised the manuscript. All authors read and approved the final manuscript.

\section{Ethics approval and consent to participate}

Not applicable.

\section{Consent for publication}

We obtained a comprehensive informed consent for the publication and presentation before the surgery.

\section{Competing interests}

The authors declare that they have no competing interests.

\section{Publisher's Note}

Springer Nature remains neutral with regard to jurisdictional claims in published maps and institutional affiliations.

\section{Author details}

${ }^{1}$ Department of General Thoracic Surgery, Seirei Hamamatsu General Hospital, 2-12-12 Sumiyoshi, Hamamatsu, Shizuoka, Japan. ${ }^{2}$ Department of Pathology, Seirei Hamamatsu General Hospital, 2-12-12 Sumiyoshi, Hamamatsu, Shizuoka, Japan. ${ }^{3}$ First Department of Surgery, Hamamatsu University school of Medicine, 1-20-1 Handa-yama, Hamamatsu, Shizuoka, Japan.
Received: 13 October 2018 Accepted: 13 December 2018

Published online: 29 December 2018

\section{References}

1. Weber T, Roth TC, Beshay M, Herrmann P, Stein R, Schmid RA. Videoassisted thoracoscopic surgery of mediastinal bronchogenic cysts in adults: a single-center experience. Ann Thorac Surg. 2004;78(3):987-91.

2. Cardillo G, Carleo F, Khalil MW, Carbone L, Treggiari S, Salvadori L, et al. Surgical treatment of benign neurogenic tumours of the mediastinum: a single institution report. Eur J Cardiothorac Surg. 2008;34(6):1210-4.

3. Muramatsu T, Shimamura M, Furuichi M, Takeshita S, Morooka H, Tanaka Y, et al. Thoracoscopic resection of mediastinal bronchogenic cysts in adults. Asian J Surg. 2011;34(1):11-4.

4. Daiko H, Fujita T, Matsumura Y, Nishimura M. A new approach for posterior mediastinal tumors: thoracoscopic resection in the prone position. Asian J Endosc Surg. 2012:5(3):138-40.

5. Shirakawa Y, Noma K, Koujima T, Maeda N, Tanabe S, Ohara T, et al. Proneposition thoracoscopic resection of posterior mediastinal lymph node metastasis from rectal cancer. World J Surg Oncol. 2015;13:45.

6. Koyanagi K, Ozawa S, Tachimori Y. Minimally invasive esophagectomy performed with the patient in a prone position: a systematic review. Surg Today. 2016;46(3):275-84.

7. Bolton JW, Shahian DM. Asymptomatic bronchogenic cysts: what is the best management? Ann Thorac Surg. 1992;53(6):1134-7.

8. Suen HC, Mathisen DJ, Grillo HC, LeBlanc J, McLoud TC, Moncure AC, et al. Surgical management and radiological characteristics of bronchogenic cysts. Ann Thorac Surg. 1993;55(2):476-81.

9. Patel SR, Meeker DP, Biscotti CV, Kirby TJ, Rice TW. Presentation and management of bronchogenic cysts in the adult. Chest. 1994;106(1):79-85.

10. Kirmani B, Kirmani B, Sogliani F. Should asymptomatic bronchogenic cysts in adults be treated conservatively or with surgery? Interact Cardiovasc Thorac Surg. 2010;11(5):649-59.

11. Amore D, Cerqua FS, Perrotta F, Cennamo A, Curcio C. Bilateral simultaneous VATS for complete resection of bilateral posterior mediastinal bronchogenic cyst: a case report. Int J Surg Case Rep. 2016;28:149-51.

12. Markar SR, Wiggins T, Antonowicz S, Zacharakis E, Hanna GB. Minimally invasive esophagectomy: lateral decubitus vs. prone positioning; systematic review and pooled analysis. Surg Oncol. 2015;24(3):212-9. 
13. Abe T, Kawai R, Uemura N, Kawakami J, Ito S, Komori K, et al. Chylous leakage from a remaining duplicated left-sided thoracic duct after esophagectomy successfully treated by ligation of the left-sided thoracic duct with left-sided video-assisted thoracoscopic surgery with the patient in the prone position. Asian J Endosc Surg. 2016;9(2):138-41.

14. Onodera Y, Nakano T, Heishi T, Sakurai T, Taniyama Y, Sato C, et al. Bilateral approach for thoracoscopic esophagectomy with lymph node dissection in the dorsal area of the thoracic aorta in patients with esophageal cancer: a report of two cases. Int J Surg Case Rep. 2017;31:154-8.

\section{Submit your manuscript to a SpringerOpen ${ }^{\circ}$} journal and benefit from:

- Convenient online submission

- Rigorous peer review

- Open access: articles freely available online

High visibility within the field

- Retaining the copyright to your article

Submit your next manuscript at $\boldsymbol{\nabla}$ springeropen.com 